\title{
TERRITÓRIO QUILOMBOLA DE CORDOARIA: EXPLORAÇÃO IMOBILIÁRIA E DA RESISTÊNCIA NEGRA
}

\author{
Rosy de Oliveira ${ }^{1}$ \\ Lilian Soares da Silva ${ }^{2}$
}

Resumo: O presente artigo apresenta uma análise descritiva do territorio da Comunidade Remanescente do Quilombo de Cordoaria - localizada na cidade de Camaçari, região metropolitana de Salvador/BA. O territorio é constituido por uma população de 234 famílias e aproximadamente 650 indivíduos residentes na localidade. Os quais, por meio da Associação da Comunidade, demandam a identificação e a delimitação da área de $27.982 \mathrm{Km}^{2}$ do seu territorio, por via do Instituto de Colonização e Reforma Agrária - INCRA - ainda em processo. O artigo segue o pressuposto de que o Estado brasileiro postergou o processo de emissão de terras para os escravizados e para os descendentes de ex-escravizados desde o final de 1883. Esse adiamento permanece reconfigurado na logica da expeculação imobiliaria insidente no Territorio da Comunidade de Cordoaria -BA, autodeclarada de Remanescente de Quilombolas no Estado Contemporaneo. O artigo descreve e analisa a memória de resistencia da Comunidade de Cordoaria concatenada com a atualidade do problema fundiário enfrentado entre a Comunidade, o Estado e as especulações dos "novos" empreendimentos imobiliários no território em questão.

Palavras-chave: Estado; Memória, Território e Resistência Quilombola

\section{TERRITORY: QUILOMBO OF CORDOARIA: REAL ESTATE AND BLACK RESISTANCE EXPLOITATION}

Abstract: This article presents a descriptive analysis of the territory of the Remaining Community of Quilombo de Cordoaria - located in the metropolitan region of Salvador / BA. The territory consists of a population of 234 families and approximately 650 individuals residing in the locality. Which, through the Community Association, demand

\footnotetext{
${ }^{1}$ Rosy de Oliveira, antropóloga, professora de Antropologia e Sociologia rural do Centro de Ciências Agrárias Ambientais e Biológicas - CCAAB/UFRB, Professora Permanente do PPGMPH - Programa de Pós Graduação Em História da África da Diáspora e dos Povos Indígenas CAHL/UFRB. Grupo de Pesquisa - NEAB/UFRB. E-mail: vivasrosy@yahoo.com.br ORCID: https://orcid.org/0000-0002-1921-8849

${ }^{2}$ Lilian Soares da Silva, Mestre em História da África da Diáspora e dos Povos Indígenas CAHL/UFRB, integrante do Grupo de Pesquisa - NEAB/UFRB. E-mail: liliansoares.sp@gmail.com ; ORCID: https://orcid.org/0000-0002-1867-7533
} 
the identification and delimitation of the $27,982 \mathrm{~km}$ area of its territory, through the Institute of Colonization and Agrarian Reform -INCRA- still in process. The article follows the assumption that the Brazilian State has postponed the process of issuing land to the enslaved and the descendants of ex-enslaved since the end of 1883. This postponement remains reconfigured in the logic of real estate speculation in the Territory of the Community of Cordoaria - BA self-declared Quilombola Remnant in the Contemporary State. The article describes and analyzes the memory of resistance of the Community of Cordoaria concatenated with the actuality of the fundamental problem faced between the Community, the State and the speculations of the new real estate developments in the territory in question.

Keywords: State Memory and Resistance Quilombola

\section{TERRITORIO QUILOMBO DE CORDOARIA: EXPLORACIÓN INMOBILIARIA Y DE RESISTENCIA NEGRA}

Resumen: Este artículo destaca un análisis descriptivo del territorio de la Comunidad Restante de Quilombo de Cordoaria en la región metropolitana de Salvador / BA. El territorio consta de una población de 234 familias y aproximadamente 650 individuos que residen en el área. Lo cual, exige la identificación y delimitación del área de $27.982 \mathrm{Km}^{2}$ de su territorio, a través del Instituto de Colonización y Reforma Agraria - INCRA / BA - aún en proceso. La publicación sigue la suposición de que el Estado brasileño ha pospuesto el proceso de emisión de tierras a esclavos y descendientes de ex esclavos desde fines de 1883. Este aplazamiento permanece reconfigurado en la lógica de la especulación inmobiliaria en otros y en este Territorio comunitario de Cordoaria, autodeclarada Quilombolas restantes en el Estado contemporáneo. Al mismo tiempo, describe y analiza la memoria de la resistencia de y en los residentes concatenados con el problema de la tierra que enfrenta la Comunidad, el Estado y las especulaciones de los "nuevos" desarrollos inmobiliarios en el territorio en cuestión.

Palabras clave: Estado, Memoria, Territorio Quilombola y Resistencia.

\section{TERRITOIRE QUILOMBO DE CORDOARIA: EXPLORATION IMMOBILIÈRE ET DE RÉSISTANCE NOIRE}

Résumé: Cet article présente une analyse descriptive du territoire de la communauté restante de Quilombo de Cordoaria dans la région métropolitaine de Salvador / BA. Le territoire comprend une population de 234 familles et environ 650 personnes résidant dans la région. Lesquels, demandent l'identification et la délimitation de la superficie de 27 $982 \mathrm{~km}^{2}$ de son territoire, à travers l'Institut de Colonisation et de Réforme Agraire INCRA / BA - toujours en cours. L'publication part de l'hypothèse que l'État brésilien a remporté le processus de délivrance de terres aux esclaves et aux descendants d'anciens esclaves depuis la fin de 1883. Ce report reste reconfiguré dans la logique de la spéculation immobilière dans d'autres et dans ce territoire communautaire de Cordoaria, autodéclaré Quilombolas restants dans l'État contemporain. Dans le même temps, il décrit et analyse la mémoire de la résistance de et chez les habitants concaténée au problème 
foncier rencontré entre la Communauté, l'État et les spéculations sur les «nouveaux» développements immobiliers sur le territoire en question.

Mots-clés: État. Mémoire. Territoire de Quilombola et résistance.

A luta individual e coletiva da população negra por respeito e legitimdade das das terras, dos seus territorios por parte do Estado brasileiro remonta ao periodo imediato da abolição da escravidão negra no Brasil. As ambiguidades do imediato, aqui grafado propositalmente em italico, suscita a maneira como Estado interpretaria o que ocorreria com a agricultura nacional de imediato, na sequecia da abolição do trabalho forçado dos ex-escravizados e escravizadas. O qual seguia o entendimento de que haveria demandas por terras. Mas, terras para quem? Obvio que a população negra resistiria, em seus diversos seguimentos para garantir o reconhecimento dos seus territorios. Nomeadamente aquela que esteve aquilombada no interior do pais e estava no apice do enfrentamento da posse definitiva das terras dos seus territorios, no momento da abolição. Pois onde houve escravidão houve quilombos e quilombolas, ou seja resistencias, cujas experiencias são passiveis de serem identicadas nas mediações das Comunidades negras autodeclaradas, na contemporaneidade, como remanescentes de quilombolas.

Este artigo apresenta uma analise descritiva do territorio da Comunidade Remanescente do Quilombo de Cordoaria - localizada na cidade de Camaçari/BA. O territorio é constituido por uma população de 234 famílias e aproximadamente 650 indivíduos residentes na localidade. Sob o código do Instituto Brasileiro de Geografia e Estatística (IBGE) n 2905701, número do ID Quilombola 1.661. Conforme a portaria no Diário Oficial da União (DOU) em 20 de Janeiro de 2006, a Comunidade possui a Certificação emitida pela Fundação Cultural Palmares no ambito do processo de número 01420.002356/2005-12.

No entanto, as incrogruencias desse processo revelam os valores da memória de resistencia dos núcleos familiares do territorio. As familias desse território demandam, por meio da Associação da Comunidade, a identificação e a delimitação da área de $27.982 \mathrm{Km}^{2}$ do seu territorio, por via do Instituto de Colonização e Reforma Agrária - INCRA - ainda em processo. Isso é a posse da Certificação, emitida pela Fundação Cultural Palmares, 
instituiçaõ publica responsavel pela emissão do referido documento, fuciona apenas como um intrumento juridico para a abertura do processo da regularização fundiaria do territorio.

Por isso territorios quilombolas em processos - torna se a principal questão presente e instigante neste artigo. Pois, de acordo com os dados do site da Fundação Cultural Palmares (FCP) informam que, das 3.311 (três mil trezentas e onze) Comunidades de Remanescentes de Quilombo existentes em todo o território nacional atualizada pela Portaria nº8/2019 - 3.040 (três mil e quarenta) Comunidades de Remanescentes possuem Certificações expedidas pelo orgão ${ }^{3}$. Isso significa dizer que o número supracitado indica que 3.040 (três mil e quarenta) Comunidades de Remanescentes de Quilombos não possuem o titulo definitivo das terras.

Com isso seguimos o pressuposto de que o Estado brasileiro postergou o processo de emissão de terras para os escravizados e para os descendentes de ex-escravizados desde o final de 1883. Esse adiamento permanece reconfigurado na logica da expeculação imobiliaria insidente no Territorio da Comunidade de Cordoaria -BA, autodeclarada e certificada como de Remanescente de Quilombolas no Estado Contemporaneo.

A Comunidade, Quilombola de Cordoaria - BA, recebeu a certificção da Fundação Cultural Palmares em 01 de Março de 2004. Concomitante a isso, a Associação da Comunidade prosseguiu com os ritos nessessarios na sua interlocução com o Instituto Nacional de Colonização e Reforma Agrária (INCRA) - instituição responsavel pela abertura e desdobramentos do processo de demarcação das terras dos territórios das Comunidades certificadas. Nessa interlocução, o processo de demarcação das terras da Comunidade de Cordoaria iniciado em 2010, no Instituto Nacional de Colonização e Reforma Agrária (INCRA) permanece em aberto. O rito subsequente, prevê a elaboração do Relatório Técnico de Identificação e Delimitação (RTID) do territorio. Nessa etapa o INCRA/BA deve constituir uma Equipe de profissionais para, após isso, prosseguir com os ritos processuais das expropriações fundiárias e emitir o Título Coletivo Definitivo das terras para a Associação Quilombola, demandada no Processo.

Nesta perspectiva, a abordagem central inside sobre, a atualidade do problema

\footnotetext{
${ }^{3}$ Certidões expedidas com os dados atualizados até a Portaria n ${ }^{\circ} 34$ de 18/02/2019
} 
fundiário enfrentado entre a Comunidade, o Estado e as especulações dos "novos" empreendimentos imobiliários no território em questão. A aplicação do método etnográfico e indiciário possibilitaram o levantamento e o cruzamento entre as fontes orais e escritas utilizadas por via da metodologia da ação participante. As analises dos documentos e dos relatos orais indicados por homens e mulheres, da geração dos mais velhos da Comunidade, apontadam os seguintes resultados. Ocorrencia de tranformação tanto do territorio da Comunidade quanto dos quilombolas; multifuncionalidade profissional. Alteração expressiva das espacilidades verdes do território; redução das áreas naturais de vegetação nativa; aumento da insidendecia de insetos no interior das casa e da circulaçao de animais peçonhetos, cobras nas proximidades das residências da localidade. E diminuição das terras, por intermédio da especulação imobiliária, no territorio da comunidade quilombola. A consequencia disso é a tendencia da transformação tanto do territorio da Comunidade quanto dos quilombolas e trabalhadores rurais em porteiros, faxineiros, diaristas, profissionais dos "condominios centrais de luxo" daquela localidade. A memória do território da Comunidade com enfaze nos vínculos existentes entre a memoria simbolica dos obejetos deixados - selecionados pelos antepassados - é realçados nas narrativas de seus descendentes no presente. As instalações dos "condominios centrais de luxo" informam a atualização da dinamica inscrita, na repetição, na instalação de usinas centrais, engenhos e fazendas centrais, ato instituido no passado imperial, como forma de assegurar a ampliação da concentração de terras, latifundio, agroindustria, agronegocio - engenhos centrais.

Com isso observa se que o Estado brasileiro cria uma dinamica muito peculiar por dentro dos processos de adiamento da emissão de terras para os escravizados e para os descendentes de ex-escravizados, desde o final de 1883. Aquele adiamento permanece reconfigurado na logica da expeculação imobiliaria insidente no Territorio da Comunidade de Cordoaria -BA, autodeclarada de Remanescente de Quilombolas no Estado Contemporaneo.

\section{AS AMBIGUIDADES DO DEBATE}

No final de 1870 e inicio de 1880, o debate político sobre a situação fundiaria e a eminente abolição da escravidão revela as ambiguidades e divergencias praticas acerca 
do tema debatido tanto na vertente emancipacionista, quanto na vertente abolicionista. Essa ultima, representada pela ala reformista do movimento. O debate, centralizado na questão das formas de manutenção da concentração do monopolio das terras e a relação da mesma com a abolição, indicava a posição de ambas vertentes. A primeira vertente, emancipacionista, representada por André Rebouças, defendia a imediata liberação da terra, compreendendo a democratização da propriedade rural como o único efetivo golpe contra a escravidão. A segunda vertente, abolicionisita, liderada por Joaquin Nabuco defendia o fim imediato da escravidão, enquanto uma das "instituições auxiliares", do monopólio territorial. ${ }^{4}$

As ambiguidades do imediato, aqui grafado propositalmente em italico, suscita a maneira como o Estado, mediado pela especulação do capital da propriedade privada,organiza a agricultura nacional relacionada com a concentração da terra de imediato, ou seja, na sequecia da abolição do trabalho forçado dos ex-escravizados e escravizadas. Mas, a tentativa de expanção dos latifundios agricolas em "núcleos de engenhos", "usinas" e "fazendas centrais", cujo objetivo era mater a concentração de terras $^{5}$, encontrou resistencia por parte da população negra que resistia e ainda resiste na luta por reconhecimento dos seus territorios.

A luta e a resistência negra, individual e coletiva, por liberdade, legitimidade e reconhecimento de seus direitos de obtenção do titulo definitivo das terras dos seus territórios atravessa o pós abolição imediato e se mantem presente, nas escaladas propugnada pelo Estado neoliberal contemporâneo.

A transversalização dos interesses articulados no Estado, seja no periodo do império, o qual se ocupou com as garantias de manutenção do monopolio das terras no imediato pós abolição ${ }^{6}$, seja no final dos anos de 1960 aos anos de 1970 marcado pelas

\footnotetext{
4 Ver: CARVALHO, Maria Alice Resende. "André Rebouças E A Questão da Liberdade".In BOTELHO,André \& SCHWARCZ, Moritz Lilía (orgs) Um Enigma Chamado Brasil: 29 Interpretes E Um País. São Paulo: Companhia das Letras, 2009, pp 50 -58.

${ }^{5}$ Segundo (CAVALHO, 2009, p.53) O conceito de 'Agricultura Nacional' elaborado por André Rebouças , em 1883, destaca a criação de engenhos, fazendas e instalação de usinas centrais, complexo agroindustrial, financiado pelo governo imperial na experiência ensaiada no Nordeste açucareiro em crise, durante a segunda metade do século XIX.

${ }^{6}$ Idem (CAVALHO,2009 p.58). O esboço do complexo agroindustrial financiado pelo governo imperial produziu uma concentração ainda maior de terras nas mãos das famílias latifundiárias.
} 
repressões e opressões da ditadura militar aos territorios de identidades - indigenas, negras e camponeses. Seja no conteporaneo demarcado pelas especulações por demandas de areas nos territorios das identidades instrumentalizadas, informam resistencias ${ }^{7}$.

Nessa linha, mesmo aquelas experiencias referenciadas nas comunidades das terras abandonadas por antigos senhores de engenhos são territorios especificos de Comunidades de Remanescentes, ou seja, são territorios de identidades politizadas ${ }^{8}$. Nos quais os avanços conquistasdos e mediados por seus sujeitos coletivos de direitos revelam o poder da articulação da nas suas relações com o Estado. Nessa perspectiva a relação entre lideranças, representações, das comunidades com o Estado são, na maioria das vezes, perpassadas por relações de tensões e conflitos

\section{DEMANDAS TERRITORIAIS}

O final dos anos de 1970 e inicio dos anos 80 evidencia as demandas da luta das comunidades negras rurais por direito à posse da terra, dos territorios historicamente por eles ocupados. A luta das comunidades negras rurais potencializada pelo aumento das tensões no campo e na cidade repercurtia em ambito nacional. No Maranhão, a comunidade quilombola de Alcântara denunciava as ações de repressão do Estado que vislumbrava contruir uma base de lançamentos de foguetes no territorio da Comunidade.

Em Goiás, os agrupamentos negros rurais conhecidos como Kalunga de Goiás enfrentavam o empreendimento da construção da hidroeléctrica Furnas e o aumento dos grileiros no território. Em Paraty, no Rio de Janeiro, a construção da rodovia BR 101 cortou ao meio o quilombo do Campinho da Independência e colocou suas terras sob cobiça de grileiros da região. Nesses três casos, a rede de resistência dos quilombolas teve apoio das Universidades Federal do Maranhão, Federal de Goiás e Estadual de Campinas nas quais a logica do papel do pesquisador, mediador engajado era realçado dentro das Comunidades.

\footnotetext{
${ }^{7}$ (OLIVEIRA, 2010 p.75) Identidades instrumentalizadas - referência ao conjunto de representação das articulações políticas, da Comunidade relacionada aos grupos e intuições externos. In: O Barulho da Terra: nem Kalunga nem camponeses. Curitiba: Progressiva,2010

${ }^{8}$ (Idem, 2010 p 81). O Barulho da Terra:nem Kalunga nem camponeses. Curitiba, Ed. Progressiva,2010
} 
A situação dos territorios, incluindo as Comunidades de Frechal ( no Maranhão, Mocambo, Ivaporunduva, Trombetas, no Pará e Rio das Rãs, na Bahia) foi debatida na Assembleia Nacional Constituinte em 1985.

As resistencias dessas Comunidades resultaram na criação da (FCP) e aprovação do Artigo 68/88 conquistas alcançadas com o apoio signifativo da rede de territos de identidades vinculadas aos pescadores, marisqueiras, ribeirinhos, sindicatos rurais e, nomeadamente movimento negro. Esses dois segmentos, especialmente o Movimento Negro Unificado - MNU foram fundantais na definição da identidade de afrodescendente, afro-brasileiro e, na criação de orgãos responsaveis pela intitucionalização dos criterios de classificação e autoclassificação dos territorios de afrobrasileiros descendentes de quilombolas ${ }^{9}$.

Conforme estabelece o Artigo 68, do Ato das Disposições Constitucionais, Transitórias da Constituição do Brasil de 1988, o termo quilombola passa a ser descrito no âmbito das competências da Fundação Cultural Palmares (FCP) criada em 1988, definindo-se: "quilombolas são descendentes de africanos escravizados que mantêm tradições culturais, de subsistência e religiosa ao longo dos séculos. Uma das funções da Fundação Cultural Palmares é formalizar a existência destas comunidades, assessorá-las juridicamente e desenvolver projetos, programas e políticas de acesso à cidadania" (PALMARES, 26/09/2018

De acordo com a Instrução Normativa n ${ }^{\circ} 20$, de 19 de setembro de 2005 o conceito de comunidades quilombolas passa a ser descrito no Instituto Nacional de Colonização e Reforma Agrária (INCRA):

As comunidades quilombolas são grupos étnicos - predominantemente constituídos pela população negra rural ou urbana -, que se autodefine a partir das relações específicas com a terra, o parentesco, o território, a ancestralidade, as tradições e práticas culturais próprias. Estima-se que em todo o País existam mais de três mil comunidades quilombolas.

INCRA, 20/11/2017.

A Normativa $\mathrm{n}^{\mathrm{0}} 20$ foi elaborada para elucidar os desdobramentos das etapas do Processo de Reconhecimento, Identificação, Delimitação, Demarcação, Expropriação, Emissão da Titulação Coletiva das terras ocupadas por comunidades remanescentes de

\footnotetext{
9 SOUZA,Florentina da Silva. Afro-descendencia em Cadernos Negros e Jornal do MNU. São Paul $\therefore$ Autentica:2005.
} 
quilombolas, conforme descrito e citado acima - no Art. 68 e no Decreto no 48887 de 20 de novembro de 2003.

Nesse cenario, em que o territorio da Comunidade de Remanescentes de Quilombolas da Cordoaria se insere, os desdobramentos do processo de autorreconhecimento das pessoas, das famílias, dos sentidos de pertencimento e dos indivíduos que compõem o território da comunidade denominada Cordoaria, foram analisados por meio do trabalho de campo,

por via da observação participante em períodos distintos das festividades, reuniões ou eventos comemorativos tradicionais da comunidade, bem como entrevistas semiestruturadas, dados socieconômicos, pesquisa documental histórica, bibliográfica e o cruzamento de fontes escritas e orais.

Mapa 1: Território da Comunidade Remanescente de Quilombo de Cordoaria e seus agrupamentos étnicos.

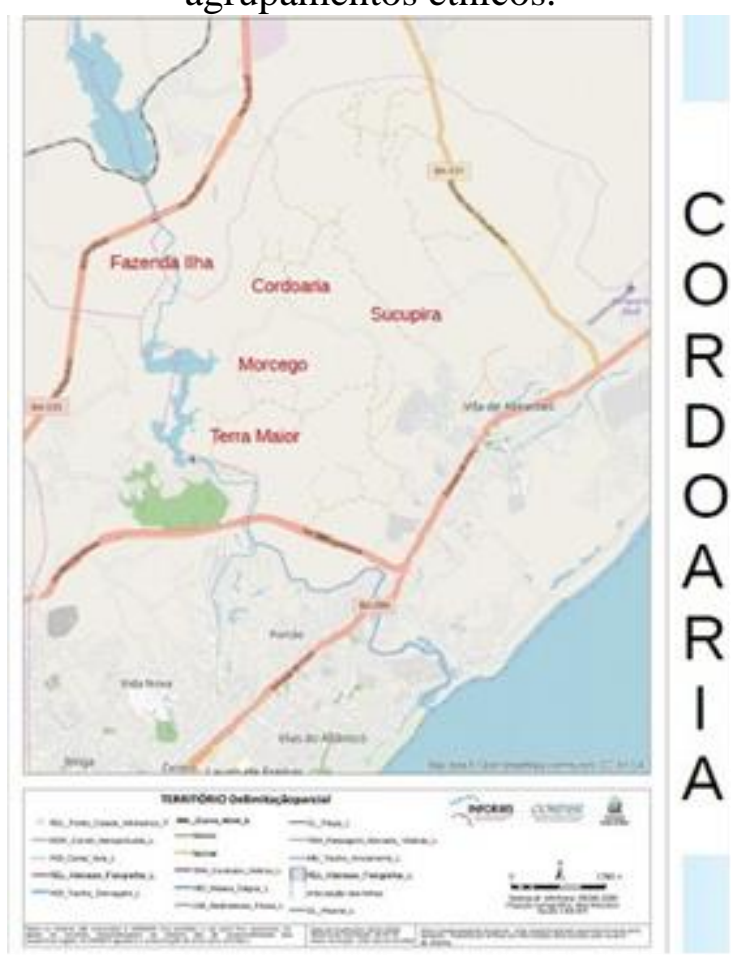

Fonte: SILVA, 2019

A análise dos dados segue a lógica interpretativa caracterizada pela análise qualitativa e quantitativa do levantamento de informações obitida em campo estruturado, por cruzamento de fontes escritas e orais, entrevistas semiestruturadas com os moradores dos agrupamentos étnicos de Sucupira e de Cordoaria, configuradas no mapa acima. No 
qual os territórios da Fazenda Ilha e Terra Maior, podem ser observados como territórios integrantes da Comunidade Remanescente de Quilombo de Cordoaria. O mapa permite identicar os agrupamentos étnicos constitutivos do atual território da Comunidade Remanescente de Quilombo de Cordoaria. Sendo eles: Sucupira, Cordoaria, Morcego, Ilha e Terra Maior.

O mapa foi elaborado com base no sistema de georreferenciamento e de delimitação territorial, sendo o recorte atual estabelecido da Estrada do Coco até a divisa com o município de Lauro de Freitas, no qual é constatado o agrupamento de Terra Maior. Territórios com uma paisagem peculiar, um modo de vida, uma cultura de existência e reexistências distintas, das quais cada morador e cada família adaptou-se a sua região e localidade, expandindo-se para as terras e adjacências vizinhas com os laços de parentesco, com o cultivo da terra, na lida com a agricultura e o trabalho, assim as famílias e as novas gerações estão em permanente construção, reconstrução e luta pelo seu direito a terra e qualidade de vida.

Do pomto de vista da memória pode se afirmar que a luta dos remanescentes, no atual Estado neoliberal esta em permanente resitencia contra a especulação do capital imobiliário, o qual em expanção da Capital Soteropolitana para o Litoral Norte, com grandes empreendimentos residenciais fechados e de alto padrão, como destacado no mapa de satélite do Empreendimento residencial Alphaville 3 e proximidade com o início do agrupamento étnico de Sucupira e seus estabelecimentos, por exemplo, a Escola Municipal de Educação Infantil de Sucupira, a Fazenda Itaparica (Paredão), o Sítio do Pica Pau Amarelo.

Mapa 2: Agrupamento étnico da comunidade e aproximação do empreendimento residencial. 


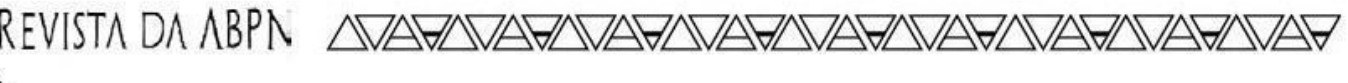

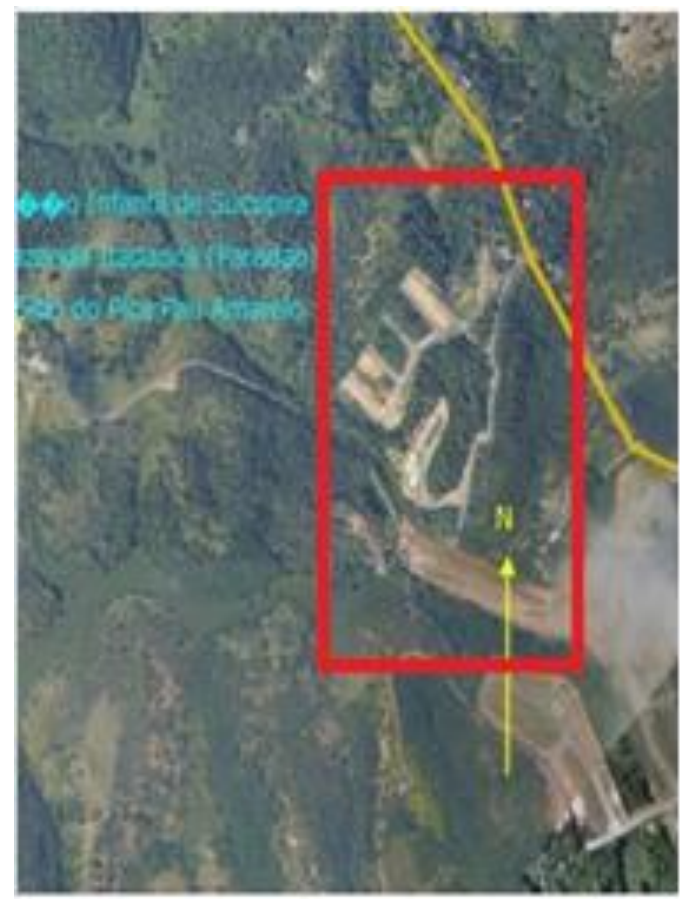

Fonte: SILVA, 2017/2018. 
No mapa constata-se a diminuição da área de vegetação natural e, em contrapartida, a ampliação de áreas construtivas. Sendo que, a região de Vila de Abrantes - englobando os municípios de Lauro de Freitas, Camaçari, Simões Filho e Salvador são integrantes da Área de Proteção Ambiental Joanes Ipitanga (APA Joanes Ipitanga). O estado da Bahia, que tem 32\% do seu território caracterizado como fragmento de Mata Atlântica, conforme lei $\mathrm{n}^{\circ}$ 11.428, e liderou o ranking de desmatamento 2015 a 2016 (Fundação SOS Mata Atlântica e INPE, 2017. O estado da Bahia possui 42 unidades de conservação (UC), sendo majoritariamente Áreas de Proteção Ambiental (APA) (INEMA, 2017). Ao todo são 32 APAs no estado (INEMA, 2017) que conforme a Lei $n^{\circ}$ 9.985, de 18 de julho de 2000 que institui o Sistema Nacional de Unidades de Conservação da Natureza - SNUC, são "áreas em geral extensas, com um certo grau de ocupação humana, dotadas de atributos abióticos, bióticos, estéticos ou culturais especialmente importantes para a qualidade de vida e o bem-estar das populações humanas, e tem como objetivos básicos proteger a diversidade biológica, disciplinar o processo de ocupação e assegurar a sustentabilidade do uso dos recursos naturais" (CONCEIÇÃO ${ }^{10}, 2017$, p. 12).

Mapa 3: Delimitação territorial da APA Joanes Ipitanga na Região Metropolitana de Salvador construído pela pesquisadora.

\footnotetext{
${ }^{10}$ CONCEIÇÃO, Taise Almeida, 2017. Contribuição para conservação da área de proteção ambiental de Joanes - Ipitanga-BA. Dissertação (Mestrado) - Universidade Federal do Recôncavo da Bahia, Centro de Ciências Agrarias, Ambientais e Biológicas. Cruz das Almas, BA, 2017. Disponível em: <https://www.ufrb.edu.br/pgrecvegetais/images/ phocadownload/Taise_Almeida_Conceição.pdf > Acesso em 26 Nov. 2018.
} 


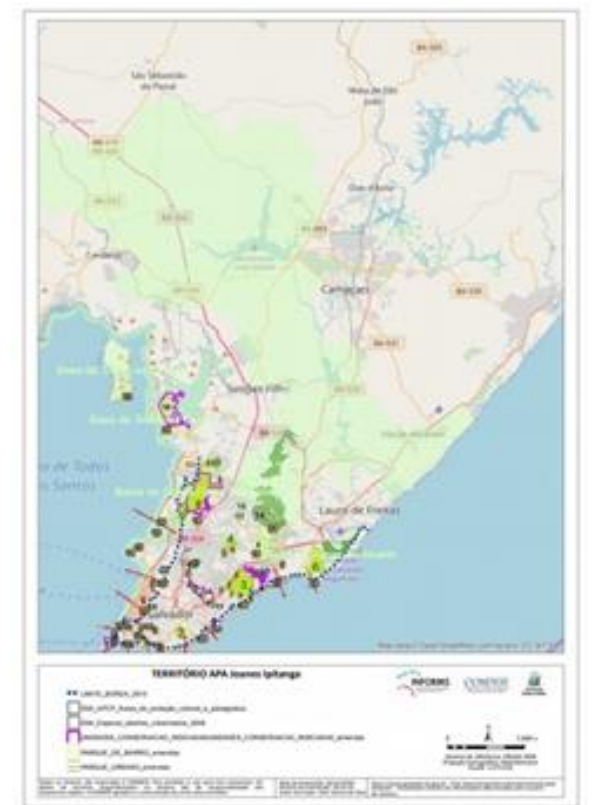

FONTE: Geopolis, 26/11/2018. 
Nas localidades próximas da Comunidade também existe outra APA, conhecida como APA Litoral Norte estendendo-se para Mata de São João - importante destacar que nos documentos históricos e processos de terra o território de Abrantes era integrado a esta Comarca e, assim mais uma das hipóteses de expansão territorial, de laços de parentesco e da territorialidade dos indígenas e quilombolas. Afirmação esta também constatada, quando a Sra. Estevan de 74 anos de idade (no documento de identidade, porque acredita ter mais idade, como ela mesma diz), nascida em Terra Maior e moradora há mais de 50 (cinquenta) anos em Cordoaria relata que:

Pela parte de minha mãe eu não alcancei [não conheci]. Meus avôs parte de pai, avô, alcancei [conheci]. Faleceu com 78 anos em Mata de São João. Sra. ESTEVAN ${ }^{11}$ - 74 anos, 31/12/2018.

Retomando a paisagem e o meio ambiente do entorno, teremos uma área de Dunas, onde também o impacto populacional e residencial tem afetado a região, conforme mapas datados dos anos de 1984 e 2016 do site ResearchGate ${ }^{3}$ sobre a ocupação das áreas urbanizadas, terras sem cobertura vegetal, remanescente de florestas densas, formações pioneiras e áreas desérticas.

Mapa 4: Ocupação do Parque Dunas de Abrantes (1984).

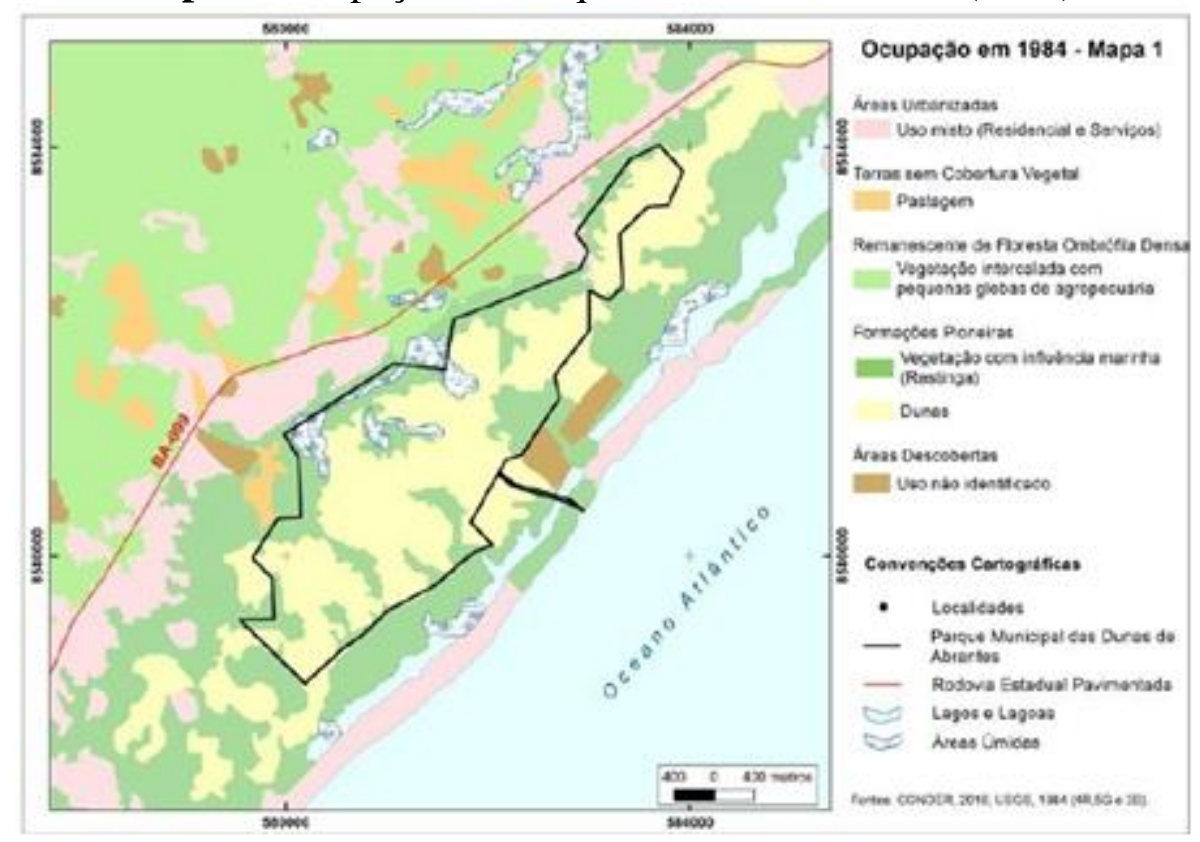

11 Entrevista concedida a pesquisadora em 31 de Dezembro de 2017, por Sra. Estevan, 74 anos de idade, nascida e criada no território quilombola. 
Fonte: ResearchGate, $05 / 2017^{12}$

Mapa 5: Ocupação do Parque Dunas de Abrantes (2016).

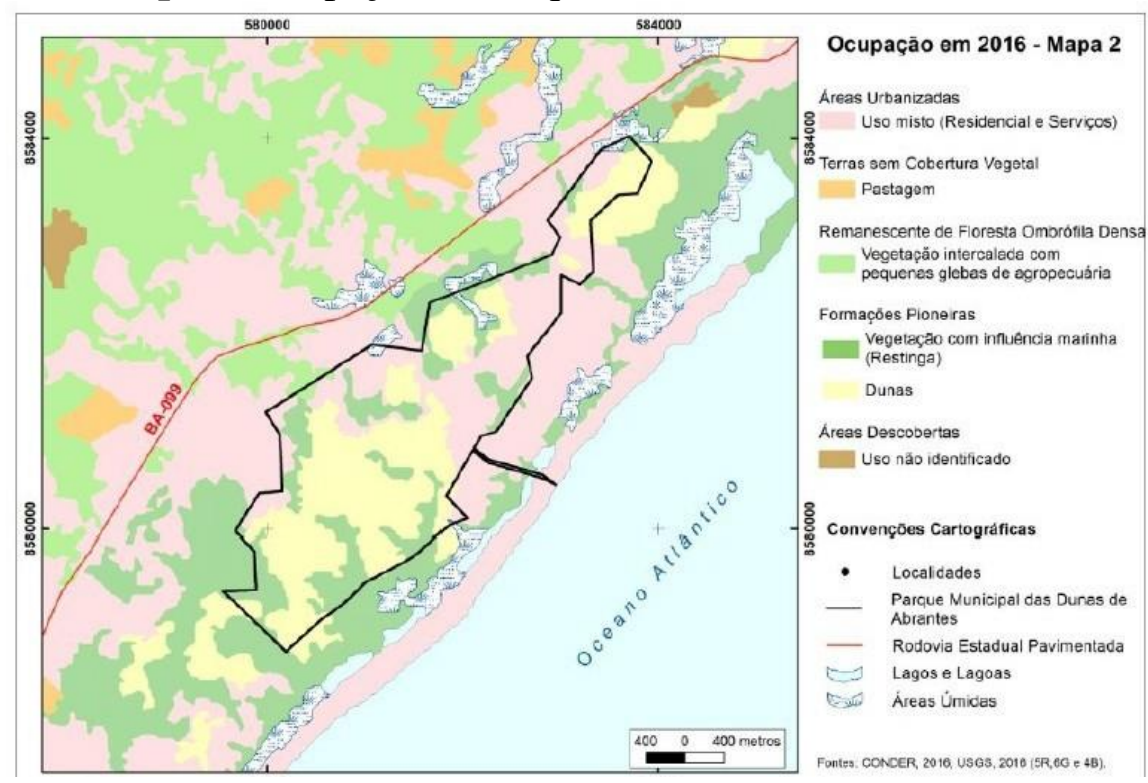

Fonte: ResearchGate, 05/2017.

A região na década de 90 era visível a amplitude das áreas verdes e das dunas permeando grande parte do território do município, todavia com a urbanização dos últimos anos e as construções residenciais, ampliou-se o espaço para os limites e invasão de áreas antes preservadas e intactas, informações estas mais detalhadas na tabela abaixo:

\footnotetext{
${ }^{12}$ ResearchGate, 05/2017. Análise espaço-temporal da ocupação da área e entorno do Parque Municipal Dunas de Abrantes, Camaçari - BA. In: BORGES, Luiz Felipe Moura Bastos; SANTOS, Desirre Alves Celestino; ZALOTI, Fabia Antunes; SANTOS, Saulo Meldrado dos; NASCIMENTO, Dária Maria Cardoso, 2017. Anais do XVIII Simpósio Brasileiro de Sensoriamento Remoto - SBSR. INPE Santos: Maio/2017. Disponível em: <https://www.researchgate.net/publication/319042242_Analise_espacotemporal_da_ocupacao_da_area_e_entorno_do_Parque_Municipal_Dunas_de_Abrantes_Camacari-BA $>$.
} 


\section{$\triangle \nabla \Delta \nabla \Delta \nabla \Delta \nabla \triangle \nabla \Delta \nabla \nabla \Delta \nabla \Delta \nabla \Delta \nabla \Delta \nabla \Delta \nabla \Delta \nabla \triangle \nabla \Delta \nabla \Delta \nabla \Delta \nabla \Delta \nabla \Delta \nabla$}

Tabela 1: Ocupação na área do Parque Dunas de Abrantes (1984 e 2016).

\begin{tabular}{|c|c|c|c|c|}
\hline Classes Mapeades & $\begin{array}{c}\text { Area hin? } \\
2016\end{array}$ & $\begin{array}{c}2016 \\
\%\end{array}$ & $\begin{array}{l}\text { Area } \mathrm{hm}^{2} \\
194\end{array}$ & $\begin{array}{l}1994 \\
\%\end{array}$ \\
\hline Areas Uthanizadas & 17,0 & 29,34 & 7,69 & 1273 \\
\hline Pastagen & 1,42 & 235 & 1,60 & 264 \\
\hline $\begin{array}{l}\text { Reanascceties de Flowesta Ontrobila } \\
\text { Densa }\end{array}$ & 9,75 & 16,16 & 13,19 & 21,85 \\
\hline Fonux,oes Pioneires-Restinga & 7,73 & 12,81 & 10,40 & 17,24 \\
\hline Fonuxiós Fioneirs - Dous & 4,6 & 7,89 & 7,68 & 12,73 \\
\hline Areas Descobertas & 0,31 & $0,5 ?$ & 0,89 & 1,4 \\
\hline Areas Conidas & 22 & 3,76 & 1,50 & 248 \\
\hline TOTAL ${ }^{*}$ & (3),94 & $72,83 \% \%$ & 42,95 & $71,17 \%$ \\
\hline
\end{tabular}

Na tabela, a analise das áreas e os percentuais das classes mapeadas no ano de 1984 e 2016 na área de estudo do município de Camaçari - Bahia evidencia o crescimento urbano passando de 7,69 $\mathrm{Km}^{2}$ (1984) a 17,70 Km² (2016) e as áreas úmidas de 1,50 (1984) para 2,27 (2016), em detrimento das outras classes mapeadas que reduziram as áreas verdes de remanescente de flores ombrófila densa de 13,19 (1984) para 9,75 (2016), formações pioneiras de restinga de 10,40 (1984) para 7,73 (2016), formações pioneiras de dunas 7,68 (1984) a 4,76 (2016), áreas descobertas de 0,89 (1984) para 0,31 (2016) e de pastagem de 1,60 (1984) para 1,42 (2016).

Desse modo constata-se a diminuição das áreas verdes e de preservação ambiental na região de Abrantes e, o aumento massivo das construções residenciais e empreendimentos imobiliários. Prova disso, é uma imagem de satélite da área localizada entre o limítrofe da Comunidade Remanescente de Cordoaria e seu entorno com o município de Abrantes (sem área verde) e o município de Lauro de Freitas - bairro do Jambeiro -, em que é possível visualizar algumas construções e também algumas áreas verdes preservadas.

Com relação ao território e a delimitação de terras ocupadas pela Comunidade de Cordoaria, teríamos uma área ou perímetro em $27.982 \mathrm{Km}$ com escala 1/18000. Tal ocupação territorial e/ou expansão é baseado nos relatos e nas memórias dos moradores, quando mencionam os pontos, os locais e os lugares que frequentavam e passavam no entorno, haja vista que, o Relatório Técnico de Identificação e Delimitação (RTID) da 
comunidade ainda não foi elaborado pelo Instituto Nacional de Colonização e Reforma Agrária (INCRA).

Cordoaria não é um bairro negro enquanto categoria de análise da cidade e do urbano, indicado por Cunha Junior (2019). A comunidade não é um bairro, porém, o espaço compreende um território e uma territorialidade negra (OLIVEIRA, 2016; OLIVEIRA, 2010).

Por fim, atualmente a comunidade dispõe de 3 (três) escolas municipais - 1 (uma) de Educação Infantil e 2 (duas) voltadas para o Ensino Fundamental I, 7 (sete) igrejas com 1 (uma) católica e as demais evangélicas das diferentes denominações ou segmentos, 3 (três) Chafarizes - responsáveis pelo abastecimento de mais de 650 (seiscentas e cinquenta) pessoas na localidade das comunidades de Sucupira e Cordoaria ${ }^{13}$, sendo que a região também abarca a Comunidade de Morcego, Terra Maior e Ilha, situadas nas proximidades do Rio Joanes e a da Barragem de Cachoeirinha, construída em meados dos anos 50, confluindo com o município de Lauro de Freitas.

Mapa 6: Delimitação do território do Quilombo de Cordoaria

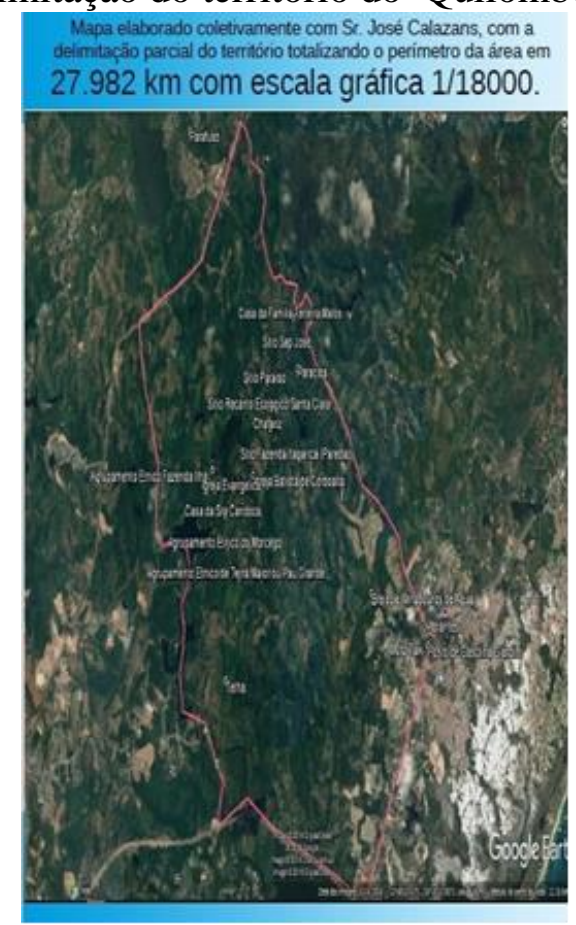

\footnotetext{
${ }^{13} \mathrm{O}$ mapa da expansão territorial da Comunidade Remanescente de Cordoaria é baseado na oralidade dos moradores mais antigos, em suas narrativas e estórias do território quilombola, assim, possibilitando a construção em programa de mapeamento e colaborativo com o Sr. José Calazan
} 
Fonte: Trabalho de campo, 2017/2018.

Nesse aspecto "o espaço deve ser considerado com um conjunto indissociável entre o homem e a natureza bruta" (SANTOS, 1988, p.10) não é o que está acontecendo e perpetuando-se na Comunidade de Cordoaria e, consequentemente afetando todo o território ou espaço quilombola. Isso porque, os empreendimentos residenciais do Alphaville, a cada ano aproximam-se das terras negras e indígenas originárias e impactam na qualidade de vida, no desenvolvimento e na subsistência da comunidade. Seja com a escassez de água nas fontes, o desmatamento das árvores e vegetação nativa, o aumento dos insetos e animais nas casas dos moradores e roças - por exemplo, Muriçocas e Cobras -, a poluição do rio e seus minadores, que são os responsáveis pelo "abastecimento" da população e, dentre outros problemas que impactam diretamente todos os indivíduos.

O empreendimento iniciou-se, segundo os interlocutores em meados de 2005, quando durante a implantação do primeiro loteamento "queriam" fechar a única via principal de acesso à Comunidade para a Vila de Abrantes -, do qual os moradores juntarem-se e conseguiram manter essa estrada em funcionamento até os dias atuais. Via essa, onde o transporte público e escolar - Camaçari/Cordoaria - se utiliza para trafegar da Estrada do Coco até a Associação de Moradores de Cordoaria e, assim a mobilidade urbana é efetivada. Efetivação essa parcial, haja vista que, alguns agrupamentos étnicos não tem acesso a este transporte, como parte de Sucupira e Cordoaria e integralmente as Comunidades de Morcego, Terra Maior e Ilha, onde os moradores descem do transporte público na Associação de Moradores de Cordoaria - ponto final - e, realizam os demais trajetos a pé, por vias de terra e cercadas pela mata - ainda preservada, o que é um risco e a insegurança - seja ela de dia ou com o cair da noite. Prova disso, pode ser constatada quando o empreendimento publiciza seu slogan "Terras Alphaville Camaçari”.

Para finalizar, o empreendimento residencial Alphaville está localizado na Estrada do Coco, com vias de acesso para o Litoral Norte e suas praias, como Costa do Sauípe, Praia do Forte, Arembepe e entre outras. Atrativos naturais estes que, podem ser um chamariz para os compradores, mas em contrapartida não se é preservado o entorno, onde as matas nativas, os brejos e os nascedouros estão reduzindo-se com o avançar das construções e afetando diretamente a comunidade quilombola, haja vista que: ocorre a redução do fluxo 
do lençol freático, não abastecendo as fontes e cisternas dos moradores; o aumento do número de insetos - muriçocas, moscas e outros animais nativos -, o aparecimento de cobras nas moradias e nas estradas de terra e, outras ocorrências ambientais e de cunho prejudicial ao meio ambiente e aos residentes da localidade.

\section{CONCLUSÃO}

As possibilidades de trasnsformações no território quilombola da Comunidade da Cordoaria estão relacionadas com os processos de fundação e aplicação do racismo estrutural e sua reconfiguração no Estado contemporaneovatual. O qual visa transformar os quilombolas, trabalhadores rurais em porteiros, faxineiros, diaristas, presos nos nucleos centrípetos de condominios de "luxo". A especulação imobiliária é um conceito continuo do rural e do urbano, sendo essa, a maior luta exógena e não interna, mas com a especulação do território, as áreas rurais e a vegetação natural estão reduzindo a passos largos, no qual é possível constatar ao longo dos anos a transformação da região, desde a quantidade de habitações residências, a migração e/ou expulsão dos moradores para empregos em outros setores - que originariamente era o trabalho com a terra, a produção de alimentos de subsistência e a venda do excedente no centro urbano -, a escassez de água nas fontes, a poluição do Rio Joanes, a incidência de cobras e o aumento expressivo de muriçocas, estes são apenas alguns dos problemas enfrentados pela população quilombola.

\section{REFERÊNCIAS BIBLIOGRÁFICAS}

BENADIBA, Laura; PLOTINSKY, Daniel (ANO). Historia oral: construcción del archivo histórico escolar. Una herramienta para la enseñanza de las ciencias sociales. Buenos Aires \& México: Ediciones Novedades Educativas, 2001. Disponível em: <https://books.google.com.br/books?id=XjLFlFq0rxwC\&printsec=frontcover\&hl=pt-

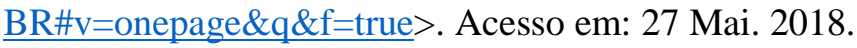

BORGES, Kátia Nogueira (2004). Abordagem etnoecológica de uma Comunidade da região metropolitana de Salvador: o caso de Cordoaria, Município de Camaçari-BA. 2004. 177 p. Dissertação de Mestrado (Mestrado em Desenvolvimento Sustentável)- Universidade de Brasília, Brasília, 2004. 
BRASIL, 2016. Incra reconhece quilombolas como beneficiários da política de reforma agrária: Portaria determina que produtores sejam inseridos nas políticas de assistência técnica (Ater), de agro industrialização (Terra Sol e Terra Forte) e de educação (PRONERA). Direitos no campo, Brasília, 21 abr. 2016. Cidadania e Justiça, p. 1. Disponível em: < http://www.incra.gov.br/media/docs/relatorio-gestao/2017/sr12-ma.pdf >. Acesso em: 27 set. 2018.

2007. Portaria $n^{o} 98$ de 26 de Novembro de 2007. Confere o art. $1^{\circ}$ da Lei $n^{\circ} 7.688$, de 22 de agosto de 1988, e considerando as atribuições conferidas à Fundação pelo Decreto $n^{o}$ 4.887, de 20 de novembro de 2003, que regulamenta o procedimento para identificação, reconhecimento, delimitação, demarcação e titulação das terras ocupadas por remanescentes das comunidades de quilombo de que trata o art. 68/ADCT, e o disposto nos arts. 215 e 216 da Constituição Federal. Disponível em: 〈http://www.palmares.gov.br/?page_id=106>

CIDADE-BRASIL (2018). Região metropolitana de Salvador. Disponível em: <https://www.cidade-brasil.com.br/regiao-metropolitana-de-salvador.html>. Acesso em: 27 set. 2018.

COMISSÃO PRÓ-ÍNDIO DE SÃO PAULO, 2009. Terra de Quilombo. Boletim 05, São Paulo, n. $5, \quad$ p. $1-4, \quad$ set. $2009 . \quad$ Disponível em: <http://www.cpisp.org.br/pdf/Boletim05_T\%20erras\%20.pdf >. Acesso em: 18 dez. 2017.

2017. Terras quilombolas: Como se titula uma terra. Disponível em:

<http://www.cpisp.org.br/terras/html/comosetitula.aspx>. Acesso em: 18 dez. 2017. 2017. Quilombos e legislação. Disponível em: <http://www.cpisp.org.br/htm/ leis/apresentacao.aspx>. Acesso em: 18 dez. 2017.

FCP, 2018. Comunidade Remanescente de Quilombo - Comunidades certificadas. Fundação Cultural Palmares. Disponível em: <http://www.palmares.gov.br/comunidades-remanescentes -de-quilombos-crqs>. Acesso 26 Set. 2018. 2018. Fundação Cultural Palmares. Disponível em: $\overline{<\mathrm{http} / / / \mathrm{ww} w}$.palmares.gov.br/?page_id=37551>. Acesso em 26 Set. 2018.

CONCEIÇÃO, Taise Almeida, 2017. Contribuição para conservação da área de proteção ambiental de Joanes - Ipitanga-BA. Dissertação (Mestrado) - Universidade Federal do Recôncavo da Bahia, Centro de Ciências Agrarias, Ambientais e Biológicas. Cruz das Almas, BA, 2017. Disponível em: <https://www.ufrb.edu.br/pgrecvegetais/images/phocadownload/ Taise_Almeida_Conceição.pdf> Acesso em 26 Nov. 2018.

CUNHA JUNIOR, Henrique. Bairros Negros: a forma urbana das populações negras no Brasil. Revista da Associação Brasileira de Pesquisadores/as Negros/as (ABPN), V. 11, N. Edição Especial, p. 65-86, maio 2019. ISSN 2177-2770. Disponível em: <https://abpnrevista.org.br/index.php/site/article/view/683>. Acesso em: 17 set. 2020.

FERREIRA, Marieta de Moraes (ORG.) História oral: desafios para o século XXI. / Marieta de Moraes Ferreira, Tânia Maria Fernandes e Verena Alberti. — Rio de Janeiro: Editora Fiocruz/Casa de Oswaldo Cruz / CPDOC - Fundação Getúlio Vargas, 2000.

GEOPOLIS, 26/11/2018. Construção de mapa pela pesquisadora do Território da Comunidade Remanescente de Quilombo da Cordoaria e seus agrupamentos étnicos.

RESEARCHGATE, 05/2017. Análise espaço-temporal da ocupação da área e entorno do Parque Municipal Dunas de Abrantes, Camaçari-BA. In: BORGES, Luiz Felipe Moura Bastos; 
SANTOS, Desirre Alves Celestino; ZALOTI, Fabia Antunes; SANTOS, Saulo Meldrado dos; NASCIMENTO, Dária Maria Cardoso, 2017. Anais do XVIII Simpósio Brasileiro de Sensoriamento Remoto - SBSR INPE. Santos,SP: Maio, 2017. Disponível em: <https://www.researchgate.net/publication/319042242_Analise_espaco-temporal_da_ocupaca o _da_area_e_entorno_do_Parque_Municipal_Dunas_de_Abrantes_Camacari-BA>.

GUSMÃO, Neusa Maria Mendes de, 2008. Antropologia, Estudos Culturais e Educação: desafios da modernidade. Revista Pro-Posições, v. 19, n. 3 (57). Campinas, SP: Unicamp, Set./dez. 2008. Disponível em: <http://www.scielo.br/pdf/pp/v19n3/v19n3a04>. Acesso 13 Ago. 2019.

GOOGLE MAPS, 2018. Localização geográfica. Disponível em: <https://www.google.com.br /maps/place/Abrantes,+Lauro+de+Freitas+-+BA/@-12.821358,-38.2905877,11z/data=!4m5! 3m41s0x7163faf377cd4ff:0x4106634a3c941a97!8m2!3d-12.8447627!4d-38.2770374>. Acesso em: 27 set. 2018.

INCRA, 19/07/2019. Relação de processos de regularização abertos no INCRA. Disponível em: <http://www.incra.gov.br/sites/default/files/incra-processosabertos-quilombolas-v2.pdf >.

Acesso 19 Jul. 2019.

15/07/2015. Quadro atual da política de regularização de territórios quilombolas no Incra. Ministério de Desenvolvimento Agrário, Instituto Nacional de Colonização e Reforma Agrária, Diretoria de Ordenamento da estrutura fundiária e Coordenação Geral de regularização de territórios quilombolas. Brasília: INCRA - DFQ, 15 Jul. 2015. Disponível em: <http://www.incra.gov.br/sites/default/files/uploads/estruturafundiaria/quilombolas/ passo_a_passo_atualizado_pdf.pdf $>$.

2014. Relatório sócio-histórico-antropológico Comunidade Quilombola de Santa Fé: Costa Marques - RO. Ministério do Desenvolvimento Agrário, Instituto Nacional de Colonização e Reforma Agrária, Superintendência Regional da Rondônia, Divisão de Ordenamento da estrutura fundiária, Serviço de Regularização de Territórios Quilombolas.

OLIVEIRA, Reinaldo José de. Territorialidade Negra e Segregação Racial na cidade de São Paulo: a luta por cidadania no século XX. São Paulo, Editora Alameda, 2016.

OLIVEIRA, Rosy. O Barulho da Terra: nem Kalunga nem camponeses. Curitiba, Editora Progressiva, 2010. Porto Velho: Rondônia, 2014. Disponível em: <http://www.consultaesic.cgu.gov.br/busca/dados/Lists/Pedido/Attachments/492916/RESPOST A_PEDIDO_Relatrio\%20Antropol gico\%20I.pdf>. Acesso em 21 Mai. 2018.

20/11/2017. Ordenamento de estrutura fundiária: Quilombolas. Disponível em: <http://www.incra.gov.br/quilombola>. Acesso 20 Nov. 2017.

PENSO, Maria Aparecida; COSTA, Liana Fortunato, 2008. A transmissão geracional em diferentes contextos: da pesquisa à intervenção / Maria Aparecida Penso, Liana Fortunato Costa (orgs.). - São Paulo: Summus, 2008. Disponível em: https://books.google.com.br/ books?id=jSQnJ-9E4xAC\&printsec $=$ frontcover $\& \mathrm{hl}=\mathrm{pt}-\mathrm{BR} \# \mathrm{v}=\mathrm{on}$ epage $\& \mathrm{q} \& \mathrm{f}=$ false $>$. Acesso em 29 Mai. 2018 as 19 h04.

PERAFÁN \& OLIVEIRA, 2013. PERAFÁN, Mireya E. Valencia e OLIVEIRA, Humberto. Território de Identidade. Coleção Política e Gestão Cultural. P55 Edições: Secretaria da Cultura do Estado da Bahia, 2013.

SANTOS, Mílton, 1988. Metamorfoses do espaço habitado: fundamentos, teórico e 
metodológicos da Geografia. / Mílton Santos. - São Paulo, SP: Hucitec, 1988.

SILVA, Lilian. Soares da. Quem disse que um quilombo é só de negros? Cordoaria um território indígena, negro e quilombola (1919-2019): subsídios técnicos para a elaboração do laudo antropológico da comunidade. Dissertação de Mestrado (Mestrado Profissional em História da África, da Diáspora e dos Povos Indígenas). Cachoeira, BA: Universidade Federal do Recôncavo da Bahia, 2019.

Recebido em: 22/09/2020

Aceito em: 30/10/2020 